\title{
MALARIA AND ANTI-MALARIAL DRUGS UTILISATION AMONG ADULTS IN A RURAL COASTAL COMMUNITY OF TANZANIA: KNOWLEDGE, ATTITUDE AND PRACTICE STUDY
}

\author{
Kigodi Neg Kigodi (MD) \\ Department of Paediatrics and Child Healthcare \\ MNH \\ \& \\ Magreth Komanya (Bsc Nursing) \\ AMREF
}

\begin{abstract}
Objective: To study malaria and examine determinants of anti-malarial drugs utilization among adults with regard to knowledge, attitudes and practices that may influence patterns of health seeking behaviour.
\end{abstract}

Design: A community based cross-sectional study carried out between December 2001 and January 2002.

Setting: A rural area of Mkuranga District in Coastal Region of Tanzania.

Subjects: A total of four hundred (400) adults composed of one hundred sixty three adult males and two hundred thirty seven adult females were interviewed.

Results: Prevalence of self-medication was found to be $44.2 \%$, males being significantly more likely to take anti-malarial drugs without medical advice than females $(52.2 \%$ vs. $38 \%)$. The level of education was found to be associated with pattern of self-medication. As regards to knowledge on malaria, only $36.8 \%$ of the respondents were knowledgeable, women being more knowledgeable than their counterpart males $(38.8 \%$ vs. $33.7 \%)$. Knowledge of malaria was significantly found to increase with advancing level of education among respondents. About two thirds of the subjects considered themselves as being at risk of malaria infection. Other factors associated with selfmedication against malaria and knowledge on malaria are discussed in this paper.

Conclusion: Prevalence of self-medication is still quite high and most people lack adequate knowledge on malaria. The individual's chronological age, level of formal education and occupation are determinants of the knowledge on malaria while gender, level of formal education and individual's occupation are factors that influence self-medication.

\section{INTRODUCTION}

Malaria is the commonest cause of fever and morbidity in the tropics ${ }^{[1]}$ and a significant source of mortality, especially among infants and young children. Every year, malaria causes clinical illness, often very severe in 300-500 million people and over a million people die from it. It threatens 2.2 billion people, about $40 \%$ of the world's population, undermining the health and welfare of the families, endangering the survival, straining both national and people's scarce resources ${ }^{[2,3]}$. In sub-Saharan Africa alone, 400 million people are at risk, and nearly all the one million deaths per annum from malaria in the world occur in this region $^{[4]}$.

In Tanzania, malaria is a major public health problem. It is the leading cause of health visits and hospital deaths, accounting for $4-5 \%$ of hospital deaths. At risk of severe illness are the pregnant women and under-five children ${ }^{[5]}$.

Resistance to chloroquine which was the first line anti-malarial in the treatment of malaria has been documented $^{[6,7]}$ and has forced change in malaria treatment policy in Tanzania. Self-medication and under-dosage with anti-malarial drugs is quite common $^{[8,9]}$ with a resultant effect on emergence and spread of resistance ${ }^{[6,7]}$. While self-medication is not only limited to chloroquine Quinine, sulphadoxine/pyrimethamine amodiaquine, halofantrine and other available anti-malarials have shown a significant resistance ${ }^{[10] .}$ It was relevant to carry out this study to examine the extent of selfmedication in a malaria holoendemic community of Tanzania. Adequate prevention and treatment of malaria in the population requires a thorough 
understanding of the knowledge of people in the community, their attitudes, perceptions and practices. It is equally important to assess determinants of knowledge and self-medications that will help to scale down the rapid increase in resistance to commonly used anti-malarial drugs.

\section{MATERIALS AND METHODS}

Study area: This study was carried out between December 2001 and January 2002. It was carried out at Mkuranga village, a malaria holoendemic area in the Coast Region. Although administratively Mkuranga is regarded as a village, characteristically people run their daily lives like people in town do and in a single structure you could have as many as five households.

Study population: For the purpose of this study adults aged fifteen years old and above from three wards (vitongoji) were enrolled and asked to participate in the study.

Data collection: A multistage random sampling technique was used to select a representative sample of 400 adults aged above fifteen years old. One village was randomly selected from Mkuranga ward. From this village three wards were randomly selected for inclusion in the study. All households in these wards were visited and from each household one subject was randomly picked out and involved in the study. Interviews was by using a pilot-pretested structured questionnaire.

Data analysis: In the present study, knowledge was measured by asking respondents on the modes of transmission, prevention, clinical features and whether malaria could be cured and

prevented. Correct responses were each scored and a 15 points scale was established. Those who scored a minimum of 7 points were regarded as knowledgeable whereas those who scored less were not. Data was analysed using Epi-info software. Statistical tests included Chi-square test and the significance test (P-value) for the difference between proportions. Association between measured variables was considered to be significant at P-value equal-to or less than 0.05 .

\section{RESULTS}

\section{Sociodemographic characteristics}

Females constituted $59.2 \%(237 / 400)$ of the total study population and the male to female ratio was approximately 7:10. The largest proportion of males was aged 25-29 years whereas that of females was 15-19. Therefore, females were more likely to be younger than males.

More than half of the respondents, 57\% (228/400) were either married or cohabiting, 10.8\% (43/400) had ever married while $32.2 \%$ (129/400) had never married. Among the study sample, $26.2 \%$ had not attended school at all, $12.3 \%$ had not completed primary school, and $48.5 \%$ had completed primary school education while only $13.0 \%$ of the respondents had attained secondary/tertiary education.

Most subjects were peasants $(41.5 \%)$, or businesspersons/petty traders $(29.5 \%)$ while $21.5 \%$ of the respondents had other uncategorized occupations. Only $7.5 \%$ of the interviewees were civil servants.

\section{Knowledge on malaria}

Of the 400 interviewees, only 147 (36.8\%) had satisfactory knowledge on malaria. The largest proportion, $60 \%(9 / 15)$ of knowledgeable subjects was aged 50-54 years. Overall, the knowledge on malaria appeared to increase with increasing chronological age. Respondents age was significantly associated with knowledge on malaria $\left[\mathrm{X}^{2}=19.11(\mathrm{df}=8) \mathrm{p}<0.01\right]$.

Although being a female was statistically insignificant with respect to knowledge on malaria, women were more likely to be knowledgeable than men $(38.8 \%$ vs. $33.7 \%)$.

Respondents who had attained a secondary or tertiary education were more likely to be knowledgeable on malaria than the rest, 33 (33/52). Generally the knowledge on malaria increased with the level of formal education acquired. Significantly the level of education appeared to influence the knowledge on malaria $\left[\mathrm{X}^{2}=36.13\right.$ $(\mathrm{df}=3) \mathrm{p}<0.000001$ ]

On the other hand civil servants were likely to be more knowledgeable on malaria 53.35\% (16/30) while peasants were the least knowledgeable $25.9 \%$ (43/166). There was a very strong association between occupation of respondents and the knowledge on malaria $\left[\mathrm{X}^{2}=15.91(\mathrm{df}=3) \mathrm{p}<\right.$ 0.001]. Table 1 
Table 1: Association between knowledge on malaria and socio-demographic factors among adults at Mkuranga District, Coast region

\begin{tabular}{|c|c|c|c|c|}
\hline Characteristics & $\begin{array}{c}\text { Interviewed } \\
(\mathbf{N}=\mathbf{4 0 0})\end{array}$ & $\begin{array}{c}\text { Knowledgeable } \\
(\%)\end{array}$ & $\mathbf{X}^{2}$ & P value \\
\hline \multicolumn{5}{|l|}{ Age groups (yrs) } \\
\hline $15-19$ & 64 & 26.6 & & \\
\hline $20-24$ & 68 & 33.8 & & \\
\hline $25-29$ & 70 & 32.9 & & \\
\hline $30-34$ & 63 & 49.2 & & \\
\hline $35-39$ & 38 & 50.0 & 19.11 & $<0.01$ \\
\hline $40-44$ & 19 & 26.3 & & \\
\hline $45-49$ & 21 & 47.6 & & \\
\hline $50-54$ & 15 & 60.0 & & \\
\hline $55+$ & 42 & 28.8 & & \\
\hline Total & 400 & 36.8 & & \\
\hline \multicolumn{5}{|l|}{ Gender: } \\
\hline Male & 163 & 33.7 & & \\
\hline Female & 237 & 38.8 & 1.07 & $>0.05$ \\
\hline \multicolumn{5}{|l|}{ Marital status: } \\
\hline Married/cohabiting & 228 & 41.2 & & \\
\hline Ever Married & 43 & 37.2 & 5.58 & $>0.05$ \\
\hline Never married & 129 & 28.7 & & \\
\hline \multicolumn{5}{|l|}{ Level of education: } \\
\hline None & 105 & 16.2 & & \\
\hline $1^{\circ}$ school incomplete & 49 & 40.8 & & \\
\hline $1^{\circ}$ school complete & 194 & 39.0 & 36.13 & $<0.000001$ \\
\hline $2^{\circ} \&$ Post $2^{\circ}$ school & 52 & 63.5 & & \\
\hline \multicolumn{5}{|l|}{ Occupation: } \\
\hline Peasants & 166 & 25.9 & & \\
\hline Civil servants & 30 & 53.3 & 15.91 & $<0.001$ \\
\hline Business-persons & 118 & 44.9 & & \\
\hline Others & 86 & 40.7 & & \\
\hline
\end{tabular}

\section{Anti-malarial drugs utilization}

Among respondents reporting to have suffered from malaria, 44.2\% (175/396) admitted taking antmalaria drugs without medical advice at least once in their life. Generally the proportion of those who admitted self-medication decreased with increasing age. Though statistically insignificant, this finding gives the impression that the younger the age, the more likely is self-medication practices.

Significantly more men than women admitted selfmedication against malaria in life $\left[\mathrm{X}^{2}=6.89(\mathrm{df}=1)\right.$ $\mathrm{p}<0.01]$.
Majority of interviewees reporting self-medication, $57.7 \%(101 / 175)$ were either married or cohabiting, $32.0 \%(56 / 175)$ had never married and 10.35 $(18 / 175)$ were those who had ever married. However there was no association.

More than three quarters of those who did not complete their primary school had practiced selfmedication against malaria. Those who had attained secondary school and tertiary education had the lowest rate of self-medication. This relationship between the level of education and self-medication was found to be statistically significant $\left[\mathrm{X}^{2}=27.01\right.$ $(\mathrm{df}=3) \mathrm{p}<0.0001]$ 
More businesspersons, 55.9\% (66/118) practiced self-medication than others. Peasants had the lowest rate of self-medication, $36.8 \%(60 / 163)$ of all groups. This relationship was statistically significant $\left[\mathrm{X}^{2}=10.32(\mathrm{df}=3) \mathrm{p}<0.05\right]$. Table 2

Table 2: Association between self medication and socio-demographic factors among adults at Mkuranga District, Coast region

\begin{tabular}{|c|c|c|c|c|}
\hline Characteristics & $\begin{array}{c}\text { Interviewed } \\
(\mathrm{N}=396)\end{array}$ & $\begin{array}{c}\text { Self medication } \\
(\%)\end{array}$ & $\mathbf{X}^{2}$ & P value \\
\hline \multicolumn{5}{|l|}{ Age groups (yrs) } \\
\hline $15-19$ & 64 & 51.6 & & \\
\hline $20-24$ & 67 & 47.8 & & \\
\hline $25-29$ & 70 & 48.6 & & \\
\hline $30-34$ & 63 & 46.0 & & \\
\hline $35-39$ & 37 & 35.1 & 7.29 & $>0.05$ \\
\hline $40-44$ & 19 & 26.3 & & \\
\hline $45-49$ & 20 & 40.0 & & \\
\hline $50-54$ & 15 & 40.0 & & \\
\hline $55+$ & 41 & 36.6 & & \\
\hline Total & 396 & 44.2 & & \\
\hline \multicolumn{5}{|l|}{ Gender: } \\
\hline Male & 159 & 52.2 & & \\
\hline Female & 237 & 38.8 & 6.89 & $<0.01$ \\
\hline \multicolumn{5}{|l|}{ Marital status: } \\
\hline Married/cohabiting & 228 & 44.3 & & \\
\hline Ever Married & 43 & 44.8 & 0.11 & $>0.05$ \\
\hline Never married & 125 & 41.9 & & \\
\hline \multicolumn{5}{|l|}{ Level of education: } \\
\hline None & 103 & 43.7 & & \\
\hline $1^{\circ}$ school incomplete & 48 & 77.1 & & \\
\hline $1^{\circ}$ school complete & 193 & 40.6 & 27.01 & $<0.00001$ \\
\hline $2^{\circ} \&$ Post $2^{\circ}$ school & 52 & 28.8 & & \\
\hline \multicolumn{5}{|l|}{ Occupation: } \\
\hline Peasants & 163 & 36.8 & & \\
\hline Civil servants & 30 & 43.3 & 10.32 & $<0.05$ \\
\hline Business-persons & 118 & 55.9 & & \\
\hline Others & 85 & 42.4 & & \\
\hline
\end{tabular}

\section{Attitudes and practices}

Out of 400 study subjects, 65.8\% (263/400) considered themselves as being at a risk of malaria infection. Among regular users of mosquito nets, $59.8 \%(134 / 224)$ said they were still at a risk of malaria infection compared to $73.3 \%$ (129/176) who did not use mosquito nets. Significantly those not using mosquito nets than users were more likely to perceive themselves as being at risk of malaria infection.

$\left[\mathrm{X}^{2}=7.93(\mathrm{df}=1) \mathrm{p}<0.005\right]$

Three quarters of subjects admitted spending few hours outdoors during night. Among respondents who frequently spent sometime outdoors at night for whatever reason, be it social or economical, two thirds said they were at risk of malaria infection as compared to $61.8 \%(63 / 102)$ of those who did not practice outdoor activities at night.

Two thirds of subjects who drained ponds or ditches around their houses considered themselves to be at a risk of malaria infection as opposed from $60.3 \%(70 / 116)$ of those who didn't.

Out of all 400 respondents, only $20.5 \%$ reported practicing regular indoor insecticide spraying. Of those, more than half perceived themselves as being 
at a risk of malaria infection while two thirds of those who did not have this practice considered themselves as being at that risk. This difference was statistically significant $\left[\mathrm{X}^{2}=5.64(\mathrm{df}=1) \mathrm{p}<\right.$ 0.05]. Table 3

Table 3: Association between risk perception and practices towards prevention of malaria infection among adults in Mkuranga District, Coast Region

\begin{tabular}{lcccc}
\hline Characteristics & $\begin{array}{c}\text { Interviewed } \\
(\mathbf{N}=\mathbf{4 0 0})\end{array}$ & $\begin{array}{c}\text { Risk perception } \\
(\%)\end{array}$ & $X^{2}$ & P value \\
\hline
\end{tabular}

\section{Use mosquito nets:}

Yes 224

No 176

Outdoor night activities:

Yes

No

298

102

Drain ponds and ditches around the house:

Yes 284

No 116

Use indoor insecticide spraying regularly:

Yes $\quad 88$

No 312

\section{DISCUSSION}

Malaria is a very common disease at Mkuranga, a holoendemic area. As such, self-medication against malaria can be anticipated in communities living in these areas. However such a practice is not without consequences, and can result into high mortality and morbidity as well as the emergence and spread of anti-malarial drug resistance.

In this study, the prevalence of self-medication was found to be high at $44.2 \%$ as previously shown in other studies ${ }^{[11]}$. The observation that significantly more men than women admitted self-medication could be explained by the fact that women pay frequent visits to health facilities due to pregnancy or related illnesses and when attending maternal and child healthcare clinics they usually receive anti-malarials for prophylaxis and chemotherapy or may be provided with prescription forms to buy drugs. Moreover the general understanding that pregnant women are at an increased risk of malaria infection among women shown in other studies ${ }^{[12]}$ may have resulted in more women seeking medical attention before taking anti-malarials. During these visits, women may have gained access to information about malaria although being a female was not a significant determinant of knowledge on malaria.

\section{8}

73.3

7.93

$<0.005$

67.1

61.8

0.96

$>0.05$

68.0

60.3

2.11

$>0.05$

54.5

68.9

5.64

$<0.05$

Respondent's level of education is an important indicator of self-medication found in the present study. Subjects with higher education are likely to be more exposed to information about malaria and are better informed about the risks associated with self-medication than those with low level of education; as such are more likely to have a broader understanding of the importance of seeking medical advice before taking any anti-malarial drugs. The observation that the rate of self-medication decreased with increasing level of education means that improving the level of formal education in the community would reduce the rate of selfmedication and consequently the associated mortality and morbidity as well as the emergence and spread of anti-malarial drug resistance.

The association between self-medication and respondent's occupation probably signifies that certain occupations may be more predisposed to self-medication than others. However since this study was not primarily intended to assess risks of individual occupations, other studies are therefore recommended.

The overall knowledge on malaria significantly appeared to increase in relation to the chronological age of respondents. This positive relationship probably indicates more exposure to information on malaria with advancing age, more episodes of 
malaria attacks and the level of formal and/or informal knowledge acquired. It would seem therefore that, the older a person gets, the more he acquires knowledge about malaria.

The fact that knowledge on malaria significantly increases with advancing level of education of the respondents implies that improving the level of education in the community would probably increase the ability of people to better gain a wider understanding of malaria. This finding is similar to studies done in this region previously [13], and elsewhere [12]. Other studies have shown that improving level of education is significantly associated with promptness in taking action for ill people ${ }^{[13]}$.

The knowledge on malaria was satisfactory among civil servants and businesspersons than peasants. Civil servants and businesspersons could be more educated and have more exposure to information on malaria and as such have better understanding of malaria.

The finding that use of mosquito nets is associated with risk perceptions of malaria infection is a subject that requires more speculation. Significantly, more respondents who reported not using mosquito nets said were at risk of malaria infection. However, the high proportion of risk perception among those reporting to be users of mosquito nets does not tally well with this practice. It is possible that use of mosquito nets may not be a regular practice among respondents in this area where people may spend some nights in their fields where they may not use mosquito nets. Moreover, since mosquito nets are very expensive fewer people could afford them and even then in limited numbers so that they may only be available to the privileged family members such as fathers as shown in the previous studies ${ }^{[14]}$. Fewer people reported regular indoor insecticide spraying in the present study. High costs of these chemicals could account to why most people did not use this method of malaria prevention on regular basis.

In the present study practices such as outdoor activities at night and draining ponds \& ditches were not found to be indicators of individual risk perception of malaria infection.

Interestingly, majority of the respondents who admitted spending at least two hours outdoors at night could not perceive themselves as being at risk of malaria infection owing to increased mosquito bites at this time. Lack of knowledge may explain this discrepancy. Among those practicing ponds/ditches drainage around their houses, a concern was surfaced about their neighbours' practices and this could explain the high proportion of risk perception among those who drained ponds/ditches around their houses compared to those who did not have this practice. Risk perception and self-medication were among factors not found to be associated with knowledge on malaria among respondents.

\section{CONCLUSION}

This study has found very high prevalence rate of self-medication among adults at Mkuranga. Results of this study suggest that policy changes on antimalarial drugs must seriously address the issue of self medication and knowledge on malaria if control of malaria is to be achieved. Since selfmedication is quite often associated with emergence and spread of drug resistance, it would be a worst of resources to continue changing drugs without taking a deep look into the causes of treatment failures of the drug in question. A long term strategy to counteract self-medication practices requires an extra effort in providing all people with formal education.

\section{ACKNOWLEDGEMENT}

The authors would like to extent special gratitude to the family of Mr. and Mrs. Komanya who sponsored this study. Our sincere thanks to $\mathrm{Mr}$ Mushi A; lecturer from Hubert Kairuki Memorial University who reviewed the original report. We would also like to thank Mkuranga District and local village administration for their cooperation.

\section{REFERENCES}

1. Manson-Bahr, PEC and Bell, DR. Malaria and babesiosis. In Manson's tropical diseases, 19th ed. London, Bailliere Tindall, 1987, pp 3-51.

2. WHO. A global strategy for malaria control. WHO Geneva 1993.93/9752-Gloor-6500.

3. WHO. Malaria twelfth programme report of the UNDP/World Bank/WHO special programme for Research and Training in Tropical disease. Tropical Disease Research Progress 1975-94: Highlights 1993-94. WHO, Geneva 1995:57-76.

4. Nevill, CG. Malaria in sub-Saharan Africa. Social Science and Medicine, 1990;31:667669 
5. Ministry of Health. National malaria control programme plan for operation. $\mathrm{MOH}$, Tanzania Mainland, 1990-1995.

6. Peters, W. Ant-malaria drug resistance an increasing problem. Br. Med. Bull. 1982:187192.

7. Drapper, CC. Brulaker, G. Geser, A. et al. Serial studies on the evolution of chloroquine resistance in an area of East Africa receiving intermittent malaria chemo-suppression. Bull World Health Organisation 1985; 63:109118.

8. Mc Combie, SC. Treatment seeking for malaria: a review of recent research. Soc. Sci. Med 1996; 43:9933-945.

9. Mnyika, KS. Killewo, JZJ and Kabalimu TK. Self-medication with antimalaria drugs in Dar es Salaam, Tanzania. Trop. Geogr. Med. 1995; 47(1):32-34.

10. Masele, AY. Sayi, J. Nsimba, SED. et al. Knowledge and management of malaria in
Dar es salaam, Tanzania. East Afr. Med. J. 1993; 70(10):639-642.

11. Foster, S. treatment of malaria outside the formal health service. J Trop Med and Hyg. 1995; 98:29-34.

12. Yenneh, H. Gyorkos, TW. Joseph, L. et al. Antimalaria drug utilization by women in Ethiopia: a knowledge, attitude and practice study. Bull of World Health Organisation.

13. Tarimo, DS. Urassa, DP. And Msamanga, GI. Caretaker's perception of clinical manifestations of childhood malaria in holoendemic rural communities in Tanzania. East Afr. Med. J. 1998; 75(2):93-96.

14. Oster, N. Krause, E and Hatz, CH. Towards a rational malaria management at district hospital level. Exploratory case series of febrile adult patients in a holoendemic rural area of Tanzania. Trop. Doct. 2000; 30:203207.

Kigodi Neg Kigodi 2005 